\title{
Interface-Constrained Layered Double Hydroxides for Stable Uranium Capture in Highly Acidic Industrial Wastewater
}

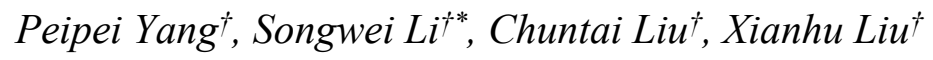

$\dagger$ National Engineering Research Center for Advanced Polymer Processing Technology, Key Laboratory of Materials Processing and Mold (Ministry of Education), Zhengzhou University, Zhengzhou 450002, China.

\section{SI.1 REAGENTS and SYNTHESIS of DFNS}

Reagents: Cyclohexane, pentanol, urea, cetylpyridinium bromide (CPB) and tetraethyl orthosilicate (TEOS) were obtained from Shanghai Aladdin Biochemical Technology Co., LTD. $\mathrm{Co}\left(\mathrm{NO}_{3}\right)_{2} \cdot 6 \mathrm{H}_{2} \mathrm{O}, \mathrm{Mg}\left(\mathrm{NO}_{3}\right)_{2} \cdot 6 \mathrm{H}_{2} \mathrm{O}, \mathrm{Na}_{2} \mathrm{CO}_{3}$ and $\mathrm{NaOH}$ were purchased from Sinopharm Chemical Reagent Co., Ltd. The materials and reagents were used without further purification.

The synthesis of dendritic fibrous nanosilica (DFNS): $30 \mathrm{~mL}$ cyclohexane and $1.5 \mathrm{~mL}$ pentanol were mixed, and named as solution $1.0 .6 \mathrm{~g}, 0.01 \mathrm{~mol}$ Urea and $1 \mathrm{~g}$, $0.0026 \mathrm{~mol} \mathrm{CPB}$ was dissolved in $30 \mathrm{~mL}$ deionized water and named as solution 2 , which was put into the solution 1 with strong stirring. $2.5 \mathrm{~g}(0.012 \mathrm{~mol})$ TEOS was dropped into the mixture and kept at room temperature for $30 \mathrm{~min}$. The emulsion was poured in a teflon-sealed reaction for $4 \mathrm{~h}$ under $150{ }^{\circ} \mathrm{C}$. After the reaction was completed, the solution contained with DFNS was cooled to ambient temperature. 
DFNS was then washed with acetone and deionized water and dried for $12 \mathrm{~h}$ in a vacuum oven. The as-synthesized material was then calcined for six hours in the atmosphere at $550^{\circ} \mathrm{C}$.

\section{SI.2 CHARACTERIZATION TEST and QA/QC PROCEDURES}

Characterization test: FTIR of the above-mentioned product was measured by Avater 370, XRD (X-ray diffraction) analysis was performed on a Rigaku D/max-IIIB diffractometer with $\mathrm{CuKa}$ irradiation $(\mathrm{Ka}=1.54178 \AA ⿻, 40 \mathrm{kV}, 150 \mathrm{~mA}) . \mathrm{N}_{2}$ adsorption/desorption isotherms were measured at the liquid nitrogen temperature $\left(-196^{\circ} \mathrm{C}\right)$ using Micromeritics ASAP2010 instrument. The specific surface areas were calculated using the BET (Brunauer-Emmett-Teller) method. Pore size distributions were calculated from the adsorption branch of the $\mathrm{N}_{2}$ adsorption/desorption isotherms using the BJH (Barrett-Joyner-Halenda) method. XPS (X-ray photoelectron spectroscopy) was measured by ESCALAB 250Xi. The morphologies of the samples were characterized using a transmission electron microscope (TEM, FEI TeDMai G2 S-Twin) and FE-SEM. Inductively Coupled Plasma-Atomic Emission Spectroscopy (ICP-AES, IRIS Intrepid II XPS) and Inductively Coupled Plasma-Mass Spectrometry instrument (ICP-MS, X SeriesII) from the Bruker company was employed to detective the concentration of metal ions.

QA/QC procedures: Quality assurance and quality control (QA/QC) was implemented carefully by duplicating all batch-scale tests under well-controlled parameters such as solution $\mathrm{pH}$, uranium concentration and adsorption dosages. In this study, each 
treatment had three replicates and take the average as the result. For solution $\mathrm{pH}$, the $\mathrm{pH}$ meter was purchased from the Mettler Toledo. Before measuring the $\mathrm{pH}$ value of the solution, the standard curve of $\mathrm{pH}$ value was established using three $\mathrm{pH}$ calibration buffers $(\mathrm{pH}=4.01, \mathrm{pH}=6.86$ and $\mathrm{pH}=9.18)$. This $\mathrm{pH}$ meter is calibrated once, when the $\mathrm{pH}$ values of 10 solutions are tested. This ensures that the $\mathrm{pH}$ value of the solution is accurate. The adsorption dosages were weighed using an analytical balance which calibrated its quality using a standard weight. The standard reference uranium solution was examined to ensure the accuracy of the methods. Standard curves of high concentration of the uranyl solution were established using seven standard solutions $\left(10,20,50,100,200,300\right.$, and $\left.400 \mathrm{mg} \mathrm{L}^{-1}\right)$. The recovery of the internal standard (90.0-99.5\%) and relative standard deviation (RSD) $(<1.00 \%)$ were continuously corrected for ICP-AES to control the quality of analysis. Meanwhile, standard curves of low concentration of the uranyl solution were established using seven standard solutions $\left(1,3,5,10,50,100\right.$, and $\left.200 \mu \mathrm{g} \mathrm{L}^{-1}\right)$. The recovery of the internal standard (89.5-99.0\%) and relative standard deviation (RSD) $(<1.00 \%)$ were continuously corrected for ICP-MS to control the quality of analysis. Reagent blanks were measured to subtract background values. 

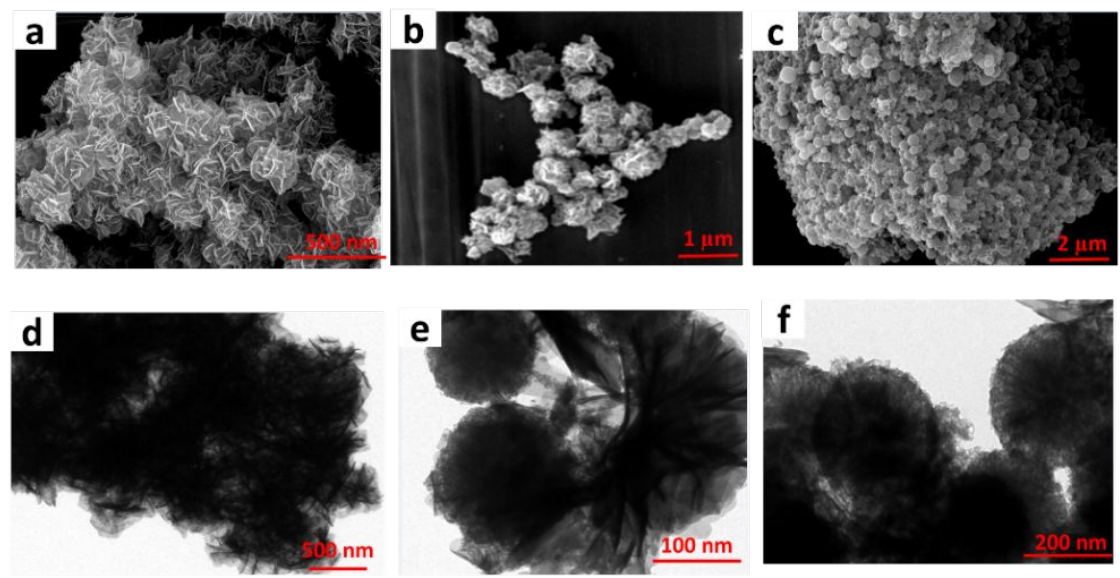

Figure S1. FE-SEM and TEM images of the prepared a, d) Mg-Co LDH, b, e) DFNS@Mg-Co LDH-1 (DFNS: $\mathrm{Mg}\left(\mathrm{NO}_{3}\right)_{2} \cdot 6 \mathrm{H}_{2} \mathrm{O}: \mathrm{Co}\left(\mathrm{NO}_{3}\right)_{2} \cdot 6 \mathrm{H}_{2} \mathrm{O}=0.05$ g:1.28 g:2.91 g) and c, f) DFNS@Mg-Co LDH-3 (DFNS:Mg(NO $\left(\mathrm{NO}_{3}\right)_{2} \cdot 6 \mathrm{H}_{2} \mathrm{O}: \mathrm{Co}\left(\mathrm{NO}_{3}\right)_{2} \cdot 6 \mathrm{H}_{2} \mathrm{O}=0.1$ $\mathrm{g}: 0.64 \mathrm{~g}: 1.45 \mathrm{~g})$.

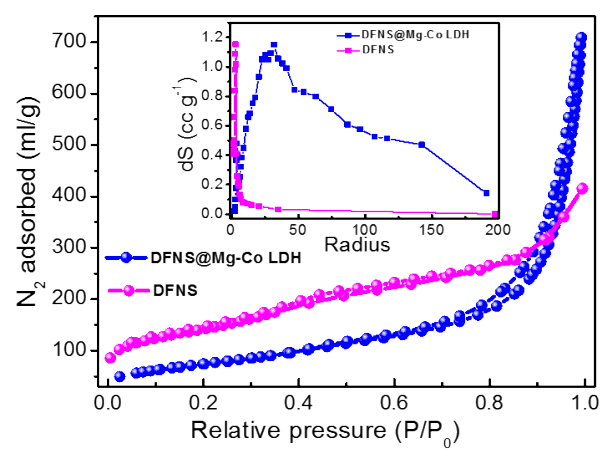

Figure S2. $\mathrm{N}_{2}$ adsorption/desorption isotherms of DFNS and DFNS@Mg-Co LDH-2.

\section{SI.3 ADSORPTION STUDIES}



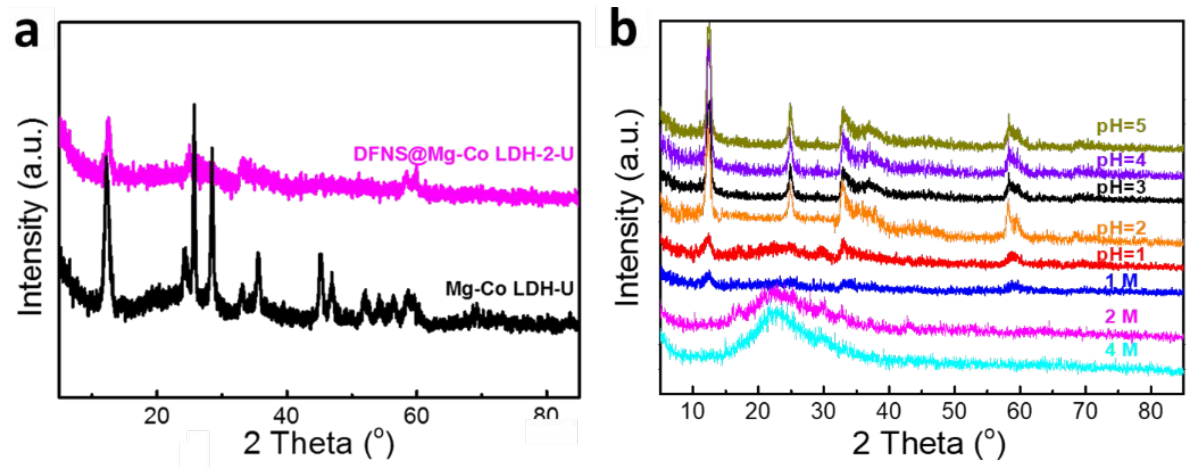

Figure S3. a) XRD patterns of Mg-Co LDH and DFNS@Mg-Co LDH-2 after uranium adsorption, b) XRD patterns of DFNS@Mg-Co LDH-2 composites under different acid conditions.

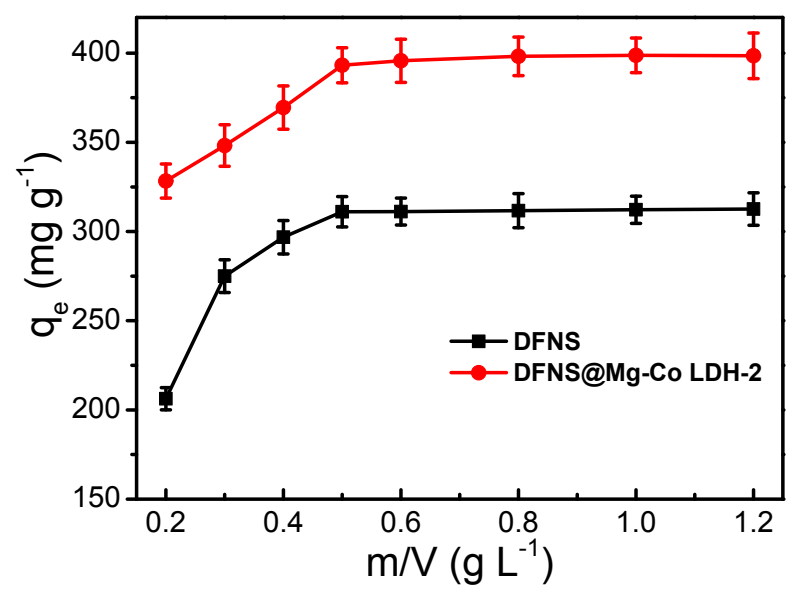

Figure S4 Effect of adsorbent dosage on adsorption capacities of DFNS and DFNS@Mg-Co LDH-2, pH =3.00; T = $25{ }^{\circ} \mathrm{C} ; \mathrm{C}_{0}=200.4 \mathrm{mg} \mathrm{L}{ }^{-1}$.
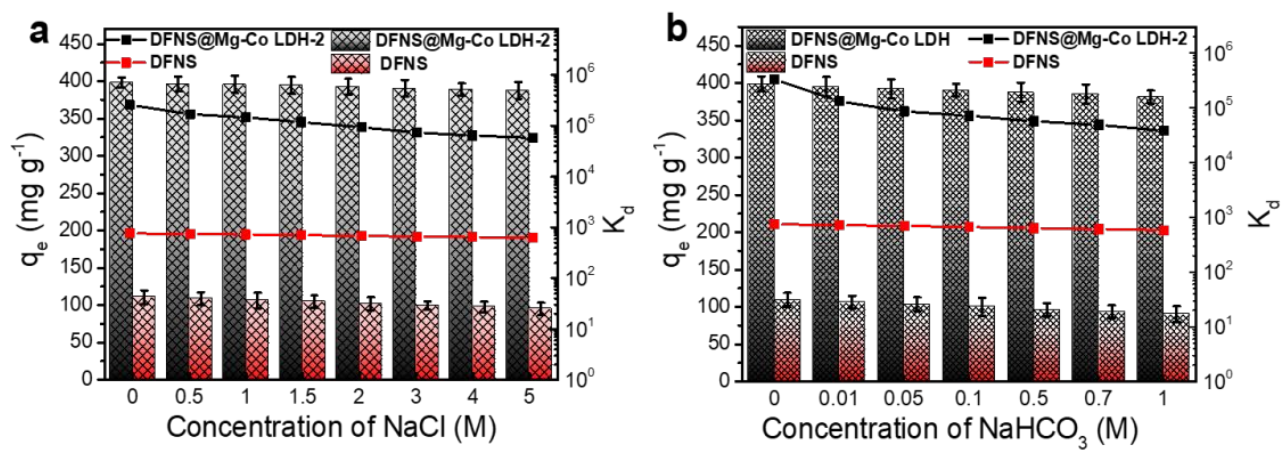

Figure S5. Effects of ionic strength on U(VI) adsorption of DFNS and DFNS@Mg-Co LDH-2. 
Kinetics studies and isotherms studies:
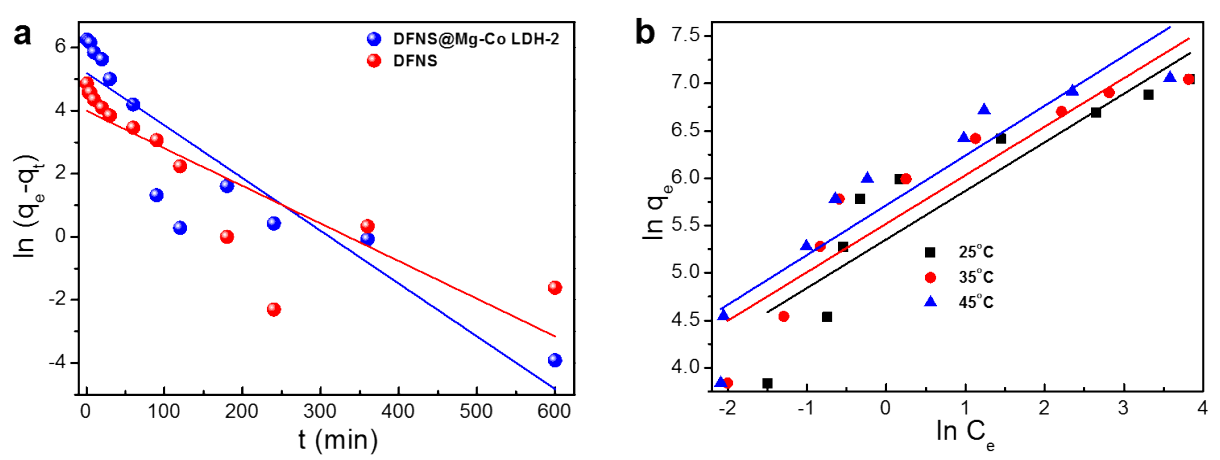

Figure S6. a) pseudo-first-order model of adsorption kinetics and b) freudlich model of adsorption isotherms.

In the study of adsorption kinetics, the pseudo-first-order, pseudo-second-order and Morris-Weber (M-W) models are employed to interpret the mechanism controlling the sorption process. The linear form of the two models can be expressed by the following Eqs. S1-S3:

$$
\begin{gathered}
\ln \left(q_{e}-q_{t}\right)=\ln q_{e}-k_{1} t \\
t / q_{t}=1 / k_{2} q_{e}^{2}+t / q_{e} \\
q_{e}=K_{i p} \sqrt{t}+C
\end{gathered}
$$

Where $\mathrm{q}_{\mathrm{t}}$ and $\mathrm{q}_{\mathrm{e}}\left(\mathrm{mg} \mathrm{g}^{-1}\right)$ are the capacity of $\mathrm{U}(\mathrm{VI})$ at time $\mathrm{t}(\mathrm{min})$ and at equilibrium, $\mathrm{K}_{\mathrm{ip}}$ is Internal diffusion constant, respectively, and $\mathrm{k}_{1}\left(\mathrm{~min}^{-1}\right)$ and $\mathrm{k}_{2}\left(\mathrm{~g} \mathrm{mg}^{-1} \mathrm{~min}^{-1}\right)$ are the respective rate constants. 
Table S1 Kinetic parameters for adsorption of $\mathrm{UO}_{2}{ }^{2+}$

\begin{tabular}{|c|c|c|c|c|c|c|c|}
\hline Kinetics model & \multicolumn{3}{|c|}{ Materials } & $\mathrm{K}$ & $\mathrm{q}^{\exp }$ & $\mathrm{qe}^{\mathrm{cal}}$ & $\mathrm{R}^{2}$ \\
\hline \multirow{2}{*}{ Pseudo-first order } & \multicolumn{3}{|c|}{ DFNS } & 0.0119 & 156 & 55 & 0.7036 \\
\hline & \multicolumn{3}{|c|}{ DFNS@Mg-Co LDH-2 } & 0.0167 & 596 & 182 & 0.8191 \\
\hline \multirow{2}{*}{ Pseudo-second order } & \multicolumn{3}{|c|}{ DFNS } & $6.3^{*} 10^{4}$ & 156 & 159 & 0.9995 \\
\hline & \multicolumn{3}{|c|}{ DFNS@Mg-Co LDH-2 } & $1.5 * 10^{4}$ & 596 & 617 & 0.999 \\
\hline Materials & $\mathrm{K}_{\mathrm{ip}}$ & $\mathrm{K}^{2}{ }_{\mathrm{ip}}$ & $\mathrm{C}_{1}$ & $\mathrm{C}_{2}$ & & $\mathrm{R}^{2}{ }_{1}$ & $\mathrm{R}^{2}{ }_{2}$ \\
\hline DFNS & 37.05 & 0.03 & 10.8 & 154.7 & & 0.9641 & 0.9394 \\
\hline DFNS@Mg-Co LDH-2 & 25.4 & 0.23 & 73.4 & 594.4 & & 0.9843 & 0.9773 \\
\hline
\end{tabular}

In order to probe the maximum adsorption capacity and the progress of adsorption, the adsorption isotherms were studied. The adsorption of U(VI) on the DFNS@Mg-Co LDH-2 composites increased with increasing temperature and the Langmuir and Freundlich models were applied to simulate experimental data.

$$
\begin{aligned}
& C_{e} / q_{e}=1 / b \cdot q_{m}+C_{e} / q_{m} \\
& \ln q_{e}=\ln k+1 / n \ln C_{e}
\end{aligned}
$$

Where $\mathrm{C}_{\mathrm{e}}\left(\mathrm{mg} \mathrm{L}^{-1}\right)$ is the equilibrated $\mathrm{U}(\mathrm{VI})$ concentration, $\mathrm{q}_{\mathrm{e}}\left(\mathrm{mg} \mathrm{g}^{-1}\right)$ is the adsorption amount of $\mathrm{U}(\mathrm{VI})$ at equilibrium. $\mathrm{K}\left(\mathrm{L} \mathrm{mg}^{-1}\right)$ is a Langmuir constant related to the energy of the adsorbent and $\mathrm{q}_{\mathrm{m}}\left(\mathrm{mg} \mathrm{g}^{-1}\right)$ is the saturation capacity at complete monolayer coverage.

$$
\begin{gathered}
\ln K_{d}=\frac{\Delta S^{\circ}}{R}-\frac{\Delta H^{\circ}}{R T} \\
K_{d}=\frac{q_{e}}{C_{e}}=\frac{\left(C_{o}-C_{e}\right)}{C_{e}} \cdot \frac{V}{m}
\end{gathered}
$$


Where $K_{d}$ stands for the distribution coefficient, $C_{e}\left(m g L^{-1}\right)$ is the equilibrated $\mathrm{U}(\mathrm{VI})$ concentration and $\mathrm{q}_{\mathrm{e}}\left(\mathrm{mg} \mathrm{g}^{-1}\right)$ represents the saturation capacity.

Table S2 Isotherm parameters for adsorption of U (VI)

\begin{tabular}{|c|c|c|c|c|c|c|c|c|}
\hline \multirow[b]{2}{*}{ Materials } & \multirow[b]{2}{*}{$\begin{array}{c}\mathrm{T} \\
(\mathrm{K})\end{array}$} & \multicolumn{4}{|c|}{ Langmuir isotherm } & \multicolumn{3}{|c|}{ Freundlich isotherm } \\
\hline & & $\begin{array}{c}\mathrm{q}^{\exp } \\
\left(\mathrm{mg} \mathrm{g}^{-1}\right)\end{array}$ & $\begin{array}{c}\mathrm{q}_{\mathrm{o}} \\
\left(\mathrm{mg} \mathrm{g}^{-1}\right)\end{array}$ & $\begin{array}{c}\mathrm{b} \\
(\mathrm{L} \\
\left.\mathrm{mg}^{-1}\right)\end{array}$ & $\mathrm{R}^{2}$ & $\begin{array}{c}\mathrm{K} \\
(\mathrm{L} \\
\left.\mathrm{mg}^{-1}\right)\end{array}$ & $\mathrm{n}$ & $\mathrm{R}^{2}$ \\
\hline \multirow{3}{*}{$\begin{array}{c}\text { DFNS@Mg-C } \\
\text { o LDH-2 }\end{array}$} & 298 & 1142 & 1198 & 0.1864 & 0.9980 & 5.35 & 1.95 & 0.9096 \\
\hline & 308 & 1143 & 1205 & 0.2687 & 0.9985 & 5.52 & 1.95 & 0.9306 \\
\hline & 318 & 1163 & 1227 & 0.2932 & 0.9989 & 5.72 & 1.9 & 0.9093 \\
\hline
\end{tabular}

Table S3 Maximum adsorption capacities of different adsorbents for uranium (VI).

\begin{tabular}{|c|c|c|c|c|c|c|}
\hline Adsorbents & $\begin{array}{l}\mathrm{q}_{\max } \\
(\mathrm{mg} \\
\left.\mathrm{g}^{-1}\right)\end{array}$ & $\begin{array}{c}\mathrm{C}_{0} \\
\left(\mathrm{mg} \mathrm{L}^{-1}\right)\end{array}$ & $\begin{array}{l}\mathrm{m} / \mathrm{V} \\
\left(\mathrm{g} \mathrm{L}^{-1}\right)\end{array}$ & $\mathrm{pH}$ & $\begin{array}{l}\text { Metal } \\
\text { ion }\end{array}$ & Ref. \\
\hline Layered double hydroxide/ graphene & 236.6 & 130 & 0.5 & 4 & $\mathrm{U}(\mathrm{VI})$ & 1 \\
\hline Carboxyl groups modified MCM-41 & 442.3 & 750 & 2 & 5 & $\mathrm{U}(\mathrm{VI})$ & 2 \\
\hline amidoxime modified MCM-41 & 297 & 750 & 2 & 5 & $\mathrm{U}(\mathrm{VI})$ & 2 \\
\hline $\begin{array}{c}\text { 2-phosphonobutane-1,2,4-tricarboxylic } \\
\text { acid-decorated chitosan-coated magnetic silica } \\
\text { nanoparticles }\end{array}$ & 105 & 150 & 1 & 4 & $\mathrm{U}(\mathrm{VI})$ & 3 \\
\hline amino-functionalized MCM-41 & 86.4 & 130 & 1 & 2 & $\mathrm{Cr}(\mathrm{VI})$ & 4 \\
\hline g- $\mathrm{C}_{3} \mathrm{~N}_{4} @$ Ni-Mg-Al-LDH & 82 & 30 & 0.5 & 5 & $\mathrm{U}(\mathrm{VI})$ & 5 \\
\hline MS-LDH & 1000 & 657.89 & 0.5 & - & $\mathrm{U}(\mathrm{VI})$ & 6 \\
\hline $\begin{array}{c}\text { carbon-conjugated covalent organic framework } \\
\text { (COF-PDAN-AO) }\end{array}$ & 256 & 190.5 & 0.5 & 4 & $\mathrm{U}(\mathrm{VI})$ & 7 \\
\hline Ni Al-LDH/ PPy & 200 & 373.1 & 0.5 & 6 & $\mathrm{U}(\mathrm{VI})$ & 8 \\
\hline Amidoxime functionalized the hydroxylated & 709 & 100 & 0.1 & 6 & $\mathrm{U}(\mathrm{VI})$ & 9 \\
\hline
\end{tabular}


SBA-15

amidoxime functionalized silica

\section{SI.4 EFFECT of CO-EXISTING IONS}

In the part of competing ions experiments, the preparation process is presented as follows: the molar ratio of $U(V I)$ and metal ions is 1:1. The corresponding concentration of $\mathrm{U}^{6+}, \mathrm{Ba}^{2+}, \mathrm{Ca}^{2+}, \mathrm{K}^{+}, \mathrm{Mg}^{+}, \mathrm{Na}^{+}, \mathrm{Ni}^{2+}, \mathrm{Sr}^{2+}, \mathrm{Th}^{4+}, \mathrm{Pb}^{2+}, \mathrm{Al}^{3+}$ and $\mathrm{Fe}^{3+}$ are listed in the Table S4.

Table S4 The concentration of the competing cations.

\begin{tabular}{ccccccc}
\hline Cations & $\mathrm{U}^{6+}$ & $\mathrm{Ba}^{2+}$ & $\mathrm{Ca}^{2+}$ & $\mathrm{K}^{+}$ & $\mathrm{Mg}^{2+}$ & $\mathrm{Th}^{4+}$ \\
\hline $\mathrm{C}_{0}\left(\mathrm{mg} \mathrm{L}^{-1}\right)$ & 198.8 & 100.7 & 31.84 & 32.61 & 20.55 & 86.2 \\
\hline & & & & & & \\
\hline Cations & $\mathrm{Al}^{3+}$ & $\mathrm{Na}^{+}$ & $\mathrm{Fe}^{3+}$ & $\mathrm{Sr}^{2+}$ & $\mathrm{Ni}^{2+}$ & $\mathrm{Pb}^{2+}$ \\
\hline $\mathrm{C}_{0}\left(\mathrm{mg} \mathrm{L}^{-1}\right)$ & 25 & 21.59 & 51.2 & 70.77 & 46.9 & 135 \\
\hline
\end{tabular}

The selectivity coefficient $\left(\mathrm{S}_{\mathrm{U}}\right)$ for $\mathrm{U}(\mathrm{VI})$, is defined as a specific term to describe the potency and degree of selectivity of the adsorbents as follows:

$$
S_{U}=\frac{K_{d}^{U}}{K_{d}^{M}}
$$

Where $K_{d}{ }^{U}$ and $K_{d}{ }^{M}$ are the distribution ratio of the $U(V I)$ ion and other competing ions in sorbent and solution, respectively.

Table S5 Selectivity coefficients $\left(\mathrm{S}_{\mathrm{U} / \mathrm{M}}\right)$ of $\mathrm{U}(\mathrm{VI})$ for different metal ions.

\begin{tabular}{ccccccc}
\hline Material & $\mathrm{Ba}$ & $\mathrm{Ca}$ & $\mathrm{K}$ & $\mathrm{Mg}$ & $\mathrm{Na}$ & $\mathrm{Ni}$ \\
\hline $\begin{array}{c}\text { DFNS@Mg-Co LDH-2 } \\
\mathrm{S}_{\mathrm{U} / \mathrm{M}}\end{array}$ & 500.7 & 21621.5 & 44403.3 & 9647.5 & 16730.9 & 2008.9 \\
\hline
\end{tabular}




\begin{tabular}{cccccc}
\hline Material & $\mathrm{Sr}$ & $\mathrm{Th}$ & $\mathrm{Al}$ & $\mathrm{Fe}$ & $\mathrm{Pb}$ \\
\hline $\begin{array}{c}\text { DFNS@Mg-Co LDH-2 } \\
\mathrm{S}_{\mathrm{U} / \mathrm{M}}\end{array}$ & 3387.6 & 1295.7 & 2165.8 & 2220.4 & 2962 \\
\hline
\end{tabular}

\section{SI.5 ADSORPTION-DESORPTION EXPERIMENTS}

5.1 U(VI) desorption experiments. The recyclability and reuse of adsorbents play an important role in the extraction of $\mathrm{U}(\mathrm{VI})$ from seawater. The eluent agents of $\mathrm{NaCl}$, citric acid, $\mathrm{HCl}, \mathrm{NaHCO}_{3}$, and $\mathrm{NaOH}$ were first investigated for desorption of $\mathrm{U}(\mathrm{VI})$. The results from Figure S7a demonstrate that citric acid is the best eluent agent for reuse and recyclability of DFNS@Mg-Co LDH-2 adsorbent. In the typical experiment, $10 \mathrm{mg}$ of adsorbent with $\mathrm{U}(\mathrm{VI})$ ions was added into $20 \mathrm{~mL}$ eluent solution, which included in $0.1 \mathrm{M} \mathrm{NaCl}, 0.1 \mathrm{M}$ citric acid, $0.1 \mathrm{M} \mathrm{HCl}, 0.1 \mathrm{M} \mathrm{NaHCO}_{3}$ and $0.1 \mathrm{M} \mathrm{NaOH}$, respectively. The flasks were stirred for specified time at room temperature, and then the solid phase was separated from the solution by centrifuge. The results were analysed with IRIS Intrepid II XPS instrument to obtain the concentrations of $U(V I)$ ions. The elution rate of $U(V I)$ ions were calculated.
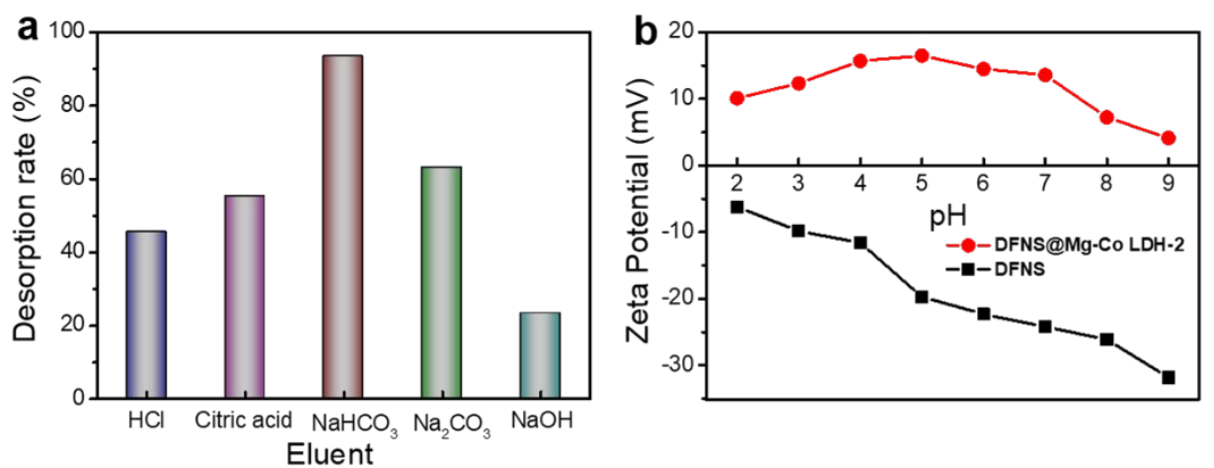

Figure S7. a) The elution efficiency of DFNS@Mg-Co LDH-2 with different eluents and b) $\zeta$-potential of DFNS and DFNS@Mg-Co LDH-2 at different pH values. 
5.2 U(VI) adsorption-desorption cycle experiments. In a typical experiment, 10 $\mathrm{mg}$ of sorbent was added into $20 \mathrm{~mL}$ of $\mathrm{U}(\mathrm{VI})$ solution and stirred for $2 \mathrm{~h}$ at room temperature. The solid phase was separated from the solution by centrifuge. Then, the adsorbent in the vacuum drying oven for $8 \mathrm{~h}$. The dried adsorbent was placed in the 20 mL eluent solution $\left(0.1 \mathrm{M} \mathrm{NaHCO}_{3}\right)$ for the $6 \mathrm{~h}$. After elution, the DFNS@Mg-Co LDH-2 was washed with abundant deionized water to remove residual $\mathrm{H}^{+}$and $\mathrm{UO}_{2}^{2+}$ until cannot detect $\mathrm{UO}_{2}{ }^{2+}$ in the aqueous solutions. The DFNS@Mg-Co LDH-2 composites were regenerated by drying at $80{ }^{\circ} \mathrm{C}$ for $12 \mathrm{~h}$ and then reused. Eventually the elution efficiency of U(VI) ions was calculated. Repeat this experiment operation for five times.

\section{SI.6 ADSORPTION MECHANISM}
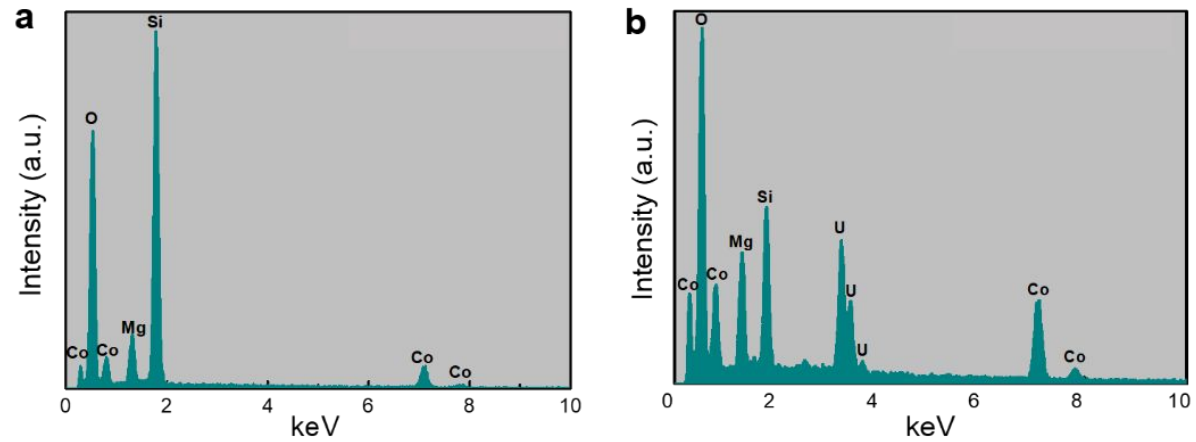

Figure S8. EDS spectra before and after uranium adsorption by DFNS@ Mg-Co LDH-2.

\section{SI.7 PREPARTION of DIFFERENT WATER ENVIRONMENT}

The modified simulated seawater was prepared as follows: $17 \mathrm{mg}$ of $\mathrm{UO}_{2}\left(\mathrm{NO}_{3}\right)_{2}, 193 \mathrm{mg}$ of $\mathrm{NaHCO}_{3}$ and $25.6 \mathrm{~g}$ of $\mathrm{NaCl}$ were dissolved in $1 \mathrm{~L}$ of deionized water, then the solution diluted to $3.34 \mu \mathrm{g} \mathrm{L}^{-1}$. 
The synthetic tap water was prepared by adding $20 \mathrm{mg}$ of $\mathrm{KNO}_{3}, 60 \mathrm{mg}$ of $\mathrm{MgSO}_{4}, 36 \mathrm{mg}$ of $\mathrm{CaCl}_{2}, 36 \mathrm{mg}$ of $\mathrm{NaHCO}_{3}, 21.1 \mathrm{mg} \mathrm{UO}_{2}\left(\mathrm{NO}_{3}\right)_{2}, 25 \mathrm{mg}$ of $\mathrm{CaSO}_{4}$, and $35 \mathrm{mg}$ of $\mathrm{Ca}\left(\mathrm{NO}_{3}\right)_{2}$ were added to $1 \mathrm{~L}$ of deionized water.

The drinking water was prepared as follows: $8.3 \mathrm{mg}$ of $\mathrm{MgSO}_{4}, 16.5 \mathrm{mg}$ of $\mathrm{MgCl}_{2}$, $19.3 \mathrm{mg}$ of $\mathrm{NaHCO}_{3}, 21.1 \mathrm{mg} \mathrm{UO}{ }_{2}\left(\mathrm{NO}_{3}\right)_{2}, 3 \mathrm{mg}$ of $\mathrm{KHCO}_{3}$, and $33 \mathrm{mg}$ of $\mathrm{CaCO}_{3}$ into $1 \mathrm{~L}$ of deionized water.

The simulated acidic mine wastewater was prepared as follows ${ }^{11}: 10.8 \mathrm{mmol}$ $\mathrm{Al}_{2}\left(\mathrm{SO}_{4}\right)_{3}, 1.08 \mathrm{mmol} \mathrm{Ca}\left(\mathrm{NO}_{3}\right)_{2}, 0.72 \mathrm{mmol} \mathrm{MgSO}_{4}, 0,053 \mathrm{mmol} \mathrm{UO}_{2}\left(\mathrm{NO}_{3}\right)_{2}$, $2.88 \mathrm{mmol} \mathrm{Na}_{2} \mathrm{SO}_{4}$ and $2.88 \mathrm{mmol}\left(\mathrm{NH}_{4}\right)_{2} \mathrm{SO}_{4}$ were dissolved in $1 \mathrm{~L}$ of deionized water.

The simulated nuclear leakage was prepared as follows: $21.1 \mathrm{mg}$ of $\mathrm{UO}_{2}\left(\mathrm{NO}_{3}\right)_{2}$, $730 \mathrm{mg}$ of $\mathrm{Ca}\left(\mathrm{NO}_{3}\right)_{2}, 30 \mathrm{mg} \mathrm{FeCl}_{2}, 200 \mathrm{mg} \mathrm{KCl}, 180 \mathrm{mg} \mathrm{Mg}\left(\mathrm{NO}_{3}\right)_{2}, 20 \mathrm{mg}$ $\mathrm{Mn}\left(\mathrm{NO}_{3}\right)_{2}$ and $1260 \mathrm{mg}$ of $\mathrm{NaCl}$ were dissolved in $1 \mathrm{~L}$ of deionized water, then the solution diluted to $0.2 \mu \mathrm{g} \mathrm{L}^{-1}$ (U(VI) ).

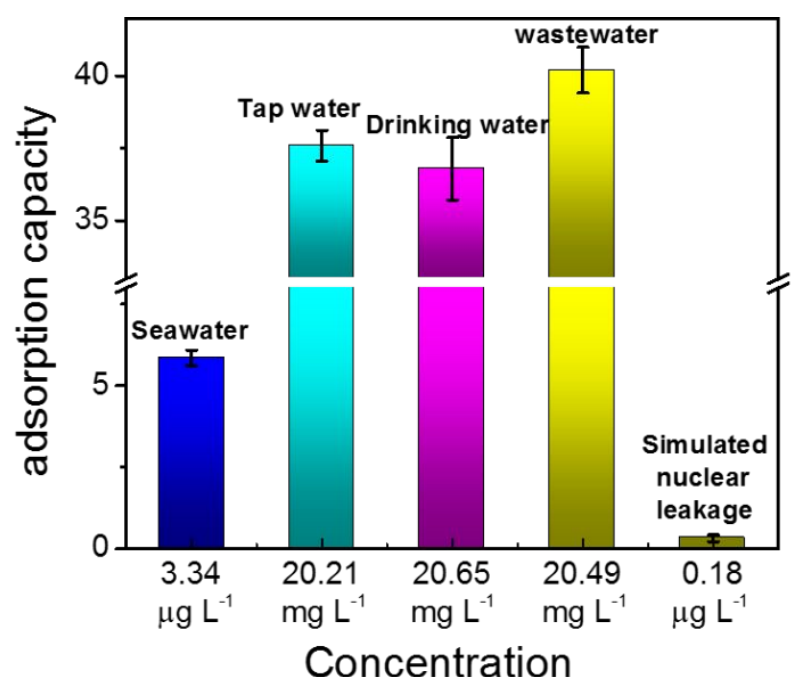

Figure S9. Adsorption amount of DFNS@Mg-Co LDH-2 in different background simulated water environment. 
Table S6. Uranium adsorption by different water environment.

\begin{tabular}{|c|c|c|c|c|c|c|}
\hline Adsorbents & $\begin{array}{c}\mathrm{q}_{\mathrm{e}} \\
\left(\mathrm{mg} \mathrm{g}^{-1}\right)\end{array}$ & $\begin{array}{c}\mathrm{C}_{0} \\
\left(\mathrm{mg} \mathrm{L}^{-1}\right)\end{array}$ & $\begin{array}{l}\mathrm{m} / \mathrm{V} \\
\left(\mathrm{g} \mathrm{L}^{-1}\right)\end{array}$ & $\mathrm{pH}$ & th) & Ref. \\
\hline amidoxime functionalized silica & 0.0051 & 0.003 & 0.5 & 8 & 6 & 10 \\
\hline Nitrogen enriched nanoporous polytriazine & 4.25 & 5 & 0.25 & 7 & 24 & 12 \\
\hline Thioacetamide modified activated carbon & 0.64 & 1.047 & 1.6 & 3.5 & 3 & 13 \\
\hline HKUST-1 & 1.01 & 2.777 & 0.25 & 4 & 24 & 14 \\
\hline 1-Arginine functionalized graphene & 0.0053 & 0.00383 & 0.5 & 8 & 4 & 15 \\
\hline hydrogel & 7 & & & & & \\
\hline $\begin{array}{l}\text { Polyamine and amidoxime modified } \\
\text { polyacrylonitrile }\end{array}$ & $\begin{array}{c}0.0065 \\
8\end{array}$ & 1.319 & 0.4 & 5 & 24 & 16 \\
\hline $\begin{array}{l}\text { Phosphonate grafted on magnetic } \\
\text { mesoporous carbon }\end{array}$ & 0.27 & 0.29 & 1 & 4 & 4 & 17 \\
\hline chitosan & 17.44 & 7.86 & 5 & 3.5 & 24 & 18 \\
\hline chitosan & 7.51 & 12.14 & 3 & 4.5 & 24 & 18 \\
\hline magnetic-Momordica charantia leaf/ chitosan & 0.098 & 1.79 & 10 & 3.3 & 1.5 & 19 \\
\hline DFNS@Mg-Co LDH-2 & $\begin{array}{c}0.0003 \\
2\end{array}$ & 0.00018 & 0.5 & 2 & 1 & $\begin{array}{c}\text { this } \\
\text { work }\end{array}$ \\
\hline DFNS@Mg-Co LDH-2 & 40.1 & 20.49 & 0.5 & 2 & 1 & $\begin{array}{l}\text { this } \\
\text { work }\end{array}$ \\
\hline DFNS@Mg-Co LDH-2 & $\begin{array}{c}0.0058 \\
6\end{array}$ & 0.00334 & 0.5 & 8 & 1 & $\begin{array}{l}\text { this } \\
\text { work }\end{array}$ \\
\hline
\end{tabular}

\section{References}

(1) Tan, L.; Wang, Y.; Liu, Q.; Wang, J.; Jing, X.; Liu, L.; Liu, J.; Song, D. Enhanced Adsorption of Uranium (VI) Using a Three-Dimensional Layered Double Hydroxide/Graphene Hybrid Material. Chem. Eng. J. 2015, 259, 752-760.

(2) Bayramoglu, G.; Arica, M. Y. MCM-41 Silica Particles Grafted with Polyacrylonitrile: Modification in to Amidoxime and Carboxyl Groups for Enhanced Uranium Removal from Aqueous Medium. Micropor. Mesopor. Mat. 2016, 226, 117-124.

(3) Huang, Y.; Zheng, H.; Li, H.; Zhao, C.; Zhao, R.; Li, S. Highly Selective Uranium 
Adsorption on 2-Phosphonobutane-1,2,4-Tricarboxylic Acid-Decorated Chitosan-Coated Magnetic Silica Nanoparticles. Chem. Eng. J. 2020, 388, 124349.

(4) Fellenz, N.; Perez-Alonso, F. J.; Martin, P. P.; García-Fierro, J. L.; Bengoa, J. F.; Marchetti, S. G.; Rojas, S. Chromium (VI) Removal from Water by Means of Adsorption-Reduction at the Surface of Amino-Functionalized MCM-41 Sorbents. Micropor. Mesopor. Mat. 2017, 239, 138-146.

(5) Zou, Y.; Wang, P.; Yao, W.; Wang, X.; Liu, Y.; Yang, D.; Wang, L.; Hou, J.; Alsaedi, A.; Hayat, T.; Wang, X. Synergistic Immobilization of $\mathrm{UO}_{2}{ }^{2+}$ by Novel Graphitic Carbon Nitride@Layered Double Hydroxide Nanocomposites from Wastewater. Chem. Eng. J. 2017, 330, 573-584.

(6) Asiabi, H.; Yamini, Y.; Shamsayei, M. Highly Efficient Capture and Recovery of Uranium by Reusable Layered Double Hydroxide Intercalated with 2-Mercaptoethanesulfonate. Chem. Eng. J. 2018, 337, 609-615.

(7) Li, F.-F.; Cui, W.-R.; Jiang, W.; Zhang, C.-R.; Liang, R.-P.; Qiu, J.-D. Stable sp² Carbon-Conjugated Covalent Organic Framework for Detection and Efficient Adsorption of Uranium from Radioactive Wastewater. J. Hazard. Mater. 2020, 392, 122333.

(8) Zhong, C.; Su, S.; Xu, L.; Liu, Q.; Zhang, H.; Yang, P.; Zhang, M.; Bai, X.; Wang, J. Preparation of NiAl-LDH/Polypyrrole Composites for Uranium(VI) Extraction from Simulated Seawater. Colloid. Surface. A 2019, 562, 329-335.

(9) Wang, X.; Ji, G.; Zhu, G.; Song, C.; Zhang, H.; Gao, C. Surface Hydroxylation of SBA-15 via Alkaline for Efficient Amidoxime-Functionalization and Enhanced Uranium Adsorption. Sep. Purif. Technol. 2019, 209, 623-635.

(10) Ahmad, M.; Wang, J.; Yang, Z.; Zhang, Q.; Zhang, B. Ultrasonic-Assisted Preparation of Amidoxime Functionalized Silica Framework via Oil-Water Emulsion Method for Selective Uranium Adsorption. Chem. Eng. J. 2020, 389, 124441.

(11) Wang, L.; Song, H.; Yuan, L.; Li, Z.; Zhang, Y.; Gibson, J. K.; Zheng, L.; Chai, Z.; Shi, W. Efficient U(VI) Reduction and Sequestration by Ti2CTx MXene. Environ. Sci. Technol. 2018, 52 (18), 10748-10756.

(12) Chaudhary, M.; Singh, L.; Rekha, P.; Srivastava, V. C.; Mohanty, P. Adsorption 
of Uranium from Aqueous Solution as well as Seawater Conditions by Nitrogen-Enriched Nanoporous Polytriazine. Chem. Eng. J. 2019, 378, 122236.

(13) Tan, Y.; Li, L.; Zhang, H.; Ding, D.; Dai, Z.; Xue, J.; Liu, J.; Hu, N.; Wang, Y. Adsorption and Recovery of U (VI) from Actual Acid Radioactive Wastewater with low Uranium Concentration Using Thioacetamide Modified Activated Carbon from Liquorice Residue. J. Radioan. Nu. Chem. 2018, 317 (2), 811-824.

(14) Yang, A.; Li, P.; Zhong, J. Facile Preparation of Low-Cost HKUST-1 with Lattice Vacancies and High-Efficiency Adsorption for Uranium. RSC Adv. 2019, 9 (18), 10320-10325.

(15) Zhu, J.; Zhang, H.; Chen, R.; Liu, Q.; Liu, J.; Yu, J.; Li, R.; Zhang, M.; Wang, J. An Anti-Algae Adsorbent for Uranium Extraction: 1-Arginine Functionalized Graphene Hydrogel Loaded with Ag Nanoparticles. J. Colloid Inter. Sci. 2019, 543, $192-200$

(16) Cheng, Y.; He, P.; Dong, F.; Nie, X.; Ding, C.; Wang, S.; Zhang, Y.; Liu, H.; Zhou, S. Polyamine and Amidoxime Groups Modified Bifunctional Polyacrylonitrile-Based Ion Exchange Fibers for Highly Efficient Extraction of U(VI) from Real Uranium Mine Water. Chem. Eng. J. 2019, 367, 198-207.

(17) Husnain, S. M.; Kim, H. J.; Um, W.; Chang, Y.-Y.; Chang, Y.-S. Superparamagnetic Adsorbent Based on Phosphonate Grafted Mesoporous Carbon for Uranium Removal. Ind. Eng. Chem. Res. 2017, 56 (35), 9821-9830.

(18) Szlachta, M.; Neitola, R.; Peräniemi, S.; Vepsäläinen, J. Effective Separation of Uranium from Mine Process Effluents Using Chitosan as a Recyclable Natural Adsorbent. Sep. Purif. Technol. 2020, 253, 117493.

(19) Yuvaraja, G.; Su, M.; Chen, D.-Y.; Pang, Y.; Kong, L.-J.; Subbaiah, M. V.; Wen, J.-C.; Reddy, G. M. Impregnation of Magnetic-Momordica Charantia Leaf Powder into Chitosan for the Removal of U(VI) from Aqueous and Polluted Wastewater. Inter. J. Bio. Macro. 2020, 149, 127-139. 